\title{
Water Adsorption and Reactions on Small Sodium Chloride Clusters
}

\author{
R. N. Barnett and Uzi Landman* \\ School of Physics, Georgia Institute of Technology, Atlanta, Georgia 30332 \\ Received: February 26, 1996; In Final Form: April 30, $1996^{\otimes}$
}

\begin{abstract}
Energetics, structures, and reactions of water with small sodium chloride clusters, $\mathrm{Na}_{4} \mathrm{Cl}_{n}, 2 \leq n \leq 4$, and of OH-doped nonstoichiometric, $\mathrm{Na}_{4} \mathrm{Cl}_{3}(\mathrm{OH}), \mathrm{Na}_{4} \mathrm{Cl}_{2}(\mathrm{OH})$, and $\mathrm{Na}_{4} \mathrm{Cl}_{2}(\mathrm{OH})_{2}$, clusters, are investigated employing electronic structure calculations using the local spin-density functional method with exchange-correlation gradient corrections in conjunction with norm-conserving nonlocal pseudopotentials, structural optimizations, and Born-Oppenheimer molecular dynamics simulations. In $\mathrm{OH}$-doped clusters an $\mathrm{OH}^{-}$is formed, substituting for the missing halide anion, and the hydroxyl anion is oriented approximately along the body diagonal of the cuboid structure of the cluster. Energetically and structurally, clusters in the sequence $\mathrm{Na}_{4} \mathrm{Cl}_{4-m}(\mathrm{OH})_{l}$ with $m=1,2$ and $1 \leq l \leq m$, are similar to the corresponding undoped clusters, $\mathrm{Na}_{4} \mathrm{Cl}_{4-m+l}$. On the stoichiometric cuboid $\mathrm{Na}_{4} \mathrm{Cl}_{4}$ cluster, a water molecule adsorbs with the molecular plane tilted by $\sim 13^{\circ}$ toward the chlorine anions with respect to the "(100) facet" of the cluster, with a binding energy of $\sim 0.49 \mathrm{eV}$. For nonstoichiometric clusters $\mathrm{Na}_{4} \mathrm{Cl}_{n}, n=2,3, \mathrm{H}_{2} \mathrm{O}$ adsorption at the halide-vacant, F-center site, with a binding energy of $\sim 0.32 \mathrm{eV}$, is accompanied by partial expulsion of the excess electron from the F-center site. This effect is correlated with a decrease in the vertical and adiabatic ionization potentials upon $\mathrm{H}_{2} \mathrm{O}$ adsorption. The thermochemistry of several reactions of water with alkali chloride clusters is evaluated. The hydrogen generation reaction, $\mathrm{Na}_{4} \mathrm{Cl}_{2}\left(\mathrm{H}_{2} \mathrm{O}\right)_{2} \rightarrow \mathrm{Na}_{4} \mathrm{Cl}_{2}(\mathrm{OH})_{2}+\mathrm{H}_{2}$, is catalyzed by the surface, with an exothermicity of $2.63 \mathrm{eV}$, and involving a barrier of $0.33 \mathrm{eV}$, compared to an exothermicity of $1.22 \mathrm{eV}$ and a barrier of 1.56 $\mathrm{eV}$ for the reaction $\mathrm{Na}_{2}\left(\mathrm{H}_{2} \mathrm{O}\right)_{2} \rightarrow(\mathrm{NaOH})_{2}+\mathrm{H}_{2}$. The mechanism of the cluster-catalyzed reaction is discussed.
\end{abstract}

\section{Introduction}

The interactions and reactions of atmospheric gases with solid sodium chloride surfaces are subjects of fundamental importance in atmospheric chemistry, since sea salt aerosols are abundant in the earth's atmosphere. ${ }^{1-7}$ Consequently, they have been investigated rather extensively (see refs $8-10$ and references to earlier work cited therein). However, while much is known about the heterogeneous reactions of trace gases (for example $\mathrm{HNO}_{3}, \mathrm{~N}_{2} \mathrm{O}_{5}, \mathrm{ClONO}_{2}$, and $\mathrm{NO}_{2}$ ) with solid $\mathrm{NaCl}$ surfaces as potential sources of reactive chlorine thus enhancing the chlorine budget and influencing the catalytic destruction of stratospheric ozone, ${ }^{11}$ information pertaining to the interaction of water molecules with such surfaces, ${ }^{9,10}$ and in particular with small sodium chloride aggregates (clusters), ${ }^{12}$ is more scarce. In addition to their relevance in atmospheric and meterological studies, as well as investigations of interstellar dust grains, ${ }^{13}$ studies of the interactions of water with salt surfaces and salt crystallites provide the opportunity to explore the properties of a highly polar molecule in a nonuniform electric field. Furthermore, investigations of such systems are of significance for understanding the nature of defects in finite ionic crystals ${ }^{14-25}$ and the role of color centers ( $\mathrm{F}$ centers) in promoting certain heterogeneous reactions involving water molecules. ${ }^{9}$

In this paper we investigated the energetics and structure of small stoichiometric and nonstoichiometric sodium chloride clusters interacting with water (e.g., $\mathrm{Na}_{2} \mathrm{Cl}_{m}\left(\mathrm{H}_{2} \mathrm{O}\right), 2 \leq m \leq 4$, and $\left.\mathrm{Na}_{4} \mathrm{Cl}_{2}\left(\mathrm{H}_{2} \mathrm{O}\right)_{2}\right)$, the energetics and pathways of several reactions, including the hydrogen generation reaction $\mathrm{Na}_{4} \mathrm{Cl}_{2}$ $+2 \mathrm{H}_{2} \mathrm{O} \rightarrow \mathrm{NaCl}_{2}\left(\mathrm{H}_{2} \mathrm{O}\right)_{2} \rightarrow \mathrm{Na}_{4} \mathrm{Cl}_{2}(\mathrm{OH})_{2}+\mathrm{H}_{2}$, and the properties of $\mathrm{OH}$-doped crystallites (e.g., $\mathrm{Na}_{4} \mathrm{Cl}_{m}(\mathrm{OH}), m=2$, 3 , and $\left.\mathrm{Na}_{4} \mathrm{Cl}_{2}(\mathrm{OH})_{2}\right)$. In our studies we employed electronic structure calculations coupled with geometry optimization based

${ }^{\otimes}$ Abstract published in Advance ACS Abstracts, August 1, 1996. on the local spin-density (LSD) functional method (with and without post-LSD exchange-correlation gradient corrections) using the molecular dynamics (MD)-LSD Born-Oppenheimer (BO) method (BO-LSD-MD) developed by us. ${ }^{26}$

Following a brief discussion of technical details in section 2 , we present our results in section 3 , and summarize in section 4.

\section{Method}

In calculations of the total energies, structural optimizations, and molecular dynamics simulations, we have used the BOLSD-MD method. ${ }^{26}$ In these calculations we have employed nonlocal norm-conserving pseudopotentials ${ }^{27}$ for the valence electrons of the oxygen, sodium, and chlorine atoms (s- and p-components, with s-nonlocality) and local pseudopotential for the hydrogens. Both LSD calculations and ones including gradient corrections, with the exchange gradient correction of Becke $^{28}$ and the correlation gradient correction of Perdew, ${ }^{29}$ were performed in a post-LSD (PLSD) mode (i.e., LSD calculations, including exchange correlation gradient corrections, performed for the geometries and densities determined from LSD structural optimizations ${ }^{26,30}$ ). In the text we quote results from PLSD calculations; a comparison between the results of LSD and PLSD calculations is given in Table 2.

As discussed in detail elsewhere, ${ }^{26}$ in our method no supercells (i.e., periodic replicas of the ionic system) are used, thus allowing studies of charged and multipolar clusters in an accurate and straightforward manner. In structural optimizations (without any constraints), using a conjugate gradient method, and in dynamical simulations, the Hellman-Feynman forces on the ions are evaluated between each optimization, or MD, step, involving iterative solution of the LSD Kohn-Sham (KS) equations, thus ensuring that the ionic trajectories are followed on the BO potential energy surface. In the LSD and PLSD 


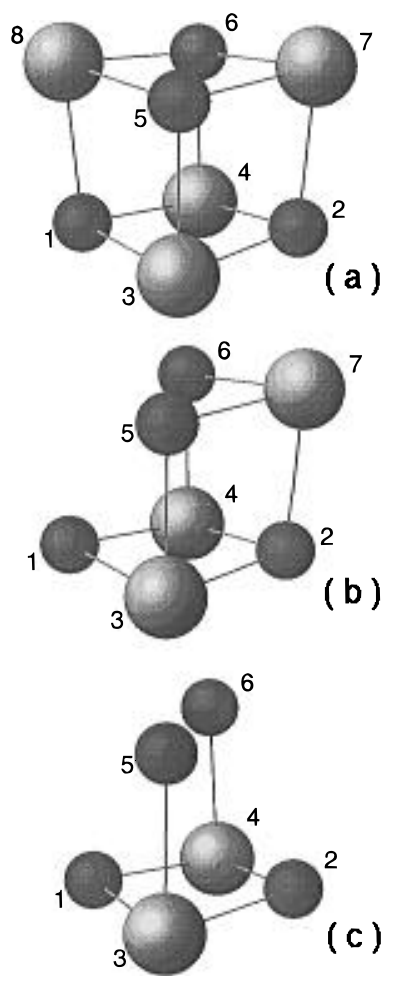

Figure 1. Optimal geometries of $\mathrm{Na}_{4} \mathrm{Cl}_{n}, 2 \leq n \leq 4$, clusters. Large and small spheres correspond to chlorine and sodium atoms, respectively, with their sizes proportional to the ionic radii. The distance $d_{\mathrm{Na}-\mathrm{Cl}}$ between neighboring ions in $\mathrm{Na}_{4} \mathrm{Cl}_{4}$ (in a) is $d_{\mathrm{Na}-\mathrm{Cl}}=2.64 \AA$.

calculations we used a plane-wave cutoff of $64 \mathrm{Ry}$. The pseudopotential $^{27}$ core radii used are

$$
\begin{aligned}
r_{\mathrm{c}}^{\mathrm{s}, \mathrm{p}}(\mathrm{O})=1.45 \mathrm{a}_{0}, \quad r_{\mathrm{c}}^{\mathrm{s}}(\mathrm{Na})=2.5 \mathrm{a}_{0}, \quad r_{\mathrm{c}}^{\mathrm{p}}(\mathrm{Na})=2.75 \mathrm{a}_{0}, \\
r_{\mathrm{c}}^{\mathrm{s}, \mathrm{p}}(\mathrm{Cl})=2.3 \mathrm{a}_{0}, \quad r_{\mathrm{c}}^{\mathrm{s}}(\mathrm{H})=0.95 \mathrm{a}_{0}
\end{aligned}
$$

where $\mathrm{s}$ and $\mathrm{p}$ denote the $\mathrm{s}$ and $\mathrm{p}$ components.

\section{Results}

(a) Doped Sodium Chloride Clusters: $\mathrm{Na}_{4} \mathrm{Cl}_{m}(\mathrm{OH}), \boldsymbol{m}=$ 2, 3, and $\mathrm{Na}_{4} \mathrm{Cl}_{2}(\mathrm{OH})_{2}$. The energetics and structures of finite stoichiometric and nonstoichiometric (excess electron) alkali halide clusters have been the subjects of intensive studies. ${ }^{14-25}$ Investigations of single and multiple F-centers in such systems, as the finite-size analogues of their well-known bulk color center counterparts, ${ }^{31}$ revealed interesting aspects pertaining to modes of localization of excess electrons in finite ionic systems. ${ }^{14-20}$ Particularly pertinent to our current studies is the finding that the excess electron(s) in nonstoichiometric clusters (i.e., $\mathrm{Na}_{n} \mathrm{Cl}_{m}$ with $m<n$ ) localize in the vacancy created by the removal of the halogen $(\mathrm{Cl})$ atom, playing a "substitutional" role and maintaining the overall cuboid structure of the corresponding stoichiometric cluster (i.e., $\mathrm{Na}_{n} \mathrm{Cl}_{n}$ ).

In Figure 1 we display the optimal structures of the $\mathrm{Na}_{4} \mathrm{Cl}_{4}$, $\mathrm{Na}_{4} \mathrm{Cl}_{3}$, and $\mathrm{Na}_{4} \mathrm{Cl}_{2}$ clusters, respectively, and in Figures 2-4 we show these structures with superimposed contours of the total electron densities, and for the nonstoichiometric ones contours of the highest occupied molecular orbital (HOMO) which occupies the excess (F-center) electron(s) (see the KS level schemes shown in Figure 5). Geometrical parameters corresponding to the structures shown in Figure 1 are given in Table 1. The optimal structures of the undoped clusters are three-dimensional cuboids (Figure 1) with the excess electron(s) localized in the F-center site(s), with some small mixing with the orbitals of the $\mathrm{Cl}^{-}$anions (Figures 2-4; see also refs 17-20).

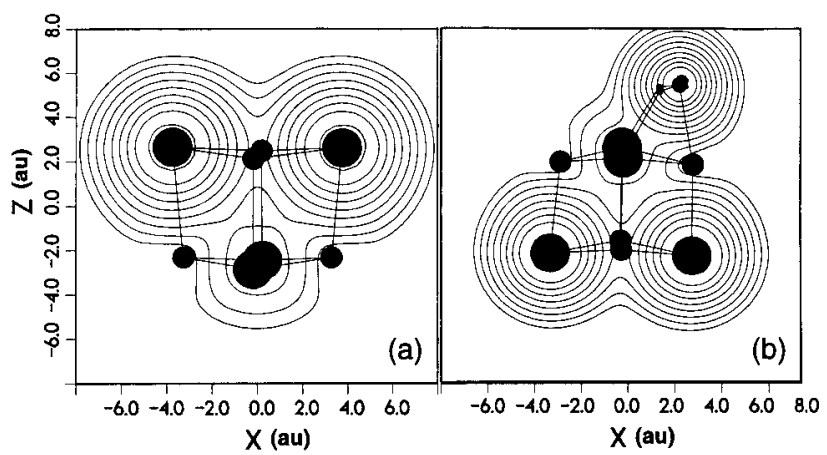

Figure 2. Optimal geometries of $\mathrm{Na}_{4} \mathrm{Cl}_{4}$ and $\mathrm{Na}_{4} \mathrm{Cl}_{4}\left(\mathrm{H}_{2} \mathrm{O}\right)$ (for the latter see also Figure 10a), with superimposed contours of the total electronic charge densities plotted in a plane through the cuboid structure containing two sodiums and two chlorines. In the case of the hydrated cluster the plane of the contours also contains the oxygen atom and the bisector of the molecular $\angle \mathrm{HOH}$ angle. Large and medium spheres represent chlorine and sodium atoms (in ratio of their ionic radii). Smaller spheres (in b) correspond to the oxygen and hydrogen atoms. The density contours are plotted as $\rho=2^{n-10}$ au, $n$ $=0,1,2, \ldots$

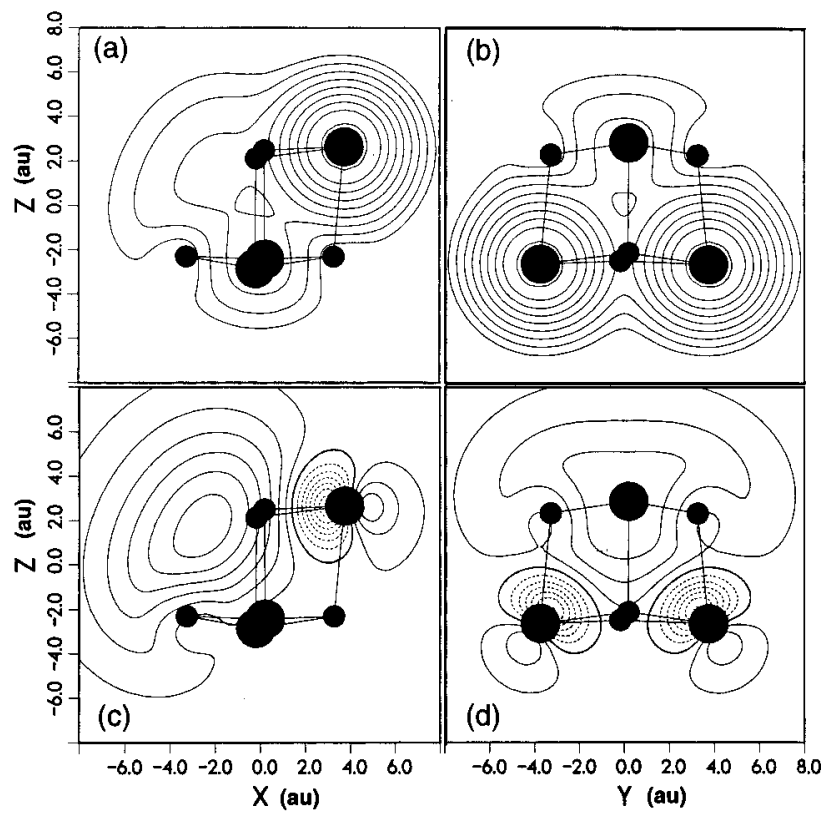

Figure 3. Optimal geometry of $\mathrm{Na}_{4} \mathrm{Cl}_{3}$ with superimposed contours of the total electronic charge density $(\mathrm{a}, \mathrm{b})$, and contours of the highest occupied Kohn-Sham (KS) orbital (HOMO) occupied by the excess electron (c, d) (solid and dashed lines correspond to positive and negative values of the wave function, respectively). For both the total charge density and the wave function contours are plotted in two orthogonal planes through the cluster $(\mathrm{a}, \mathrm{b})$ and $(\mathrm{c}, \mathrm{d})$. Note preferential localization of the excess electron at the F-center site, and some degree of mixing with the chlorine anions orbitals (c and d). The HOMO contour spacing is $0.01 \mathrm{au}$; the density contours are plotted as $2^{n-10}$ au with $n=0,1,2, \ldots$.

The optimal geometric structures of the mixed (OH-doped) clusters $\left(\mathrm{Na}_{4} \mathrm{Cl}_{3}(\mathrm{OH}), \mathrm{Na}_{4} \mathrm{Cl}_{2}(\mathrm{OH})\right.$, and $\left.\mathrm{Na}_{4} \mathrm{Cl}_{2}(\mathrm{OH})_{2}\right)$ are shown in Figure 6 (and the corresponding geometrical parameters are given in Table 1), exhibiting an alignment of the hydroxyl anion(s) $\left(\mathrm{OH}^{-}\right)$, which is (are) localized at the halide vacancy (vacancies) along the [111] body-diagonal of the approximate cubic structure. This orientation is different from that of hydroxyl anions in $\mathrm{KCl}$, solids, where the dipoles are oriented along the [100] axes of the crystal. ${ }^{31,32}$ Electronic charge distributions and HOMO contours for $\mathrm{OH}$-doped clusters are shown in Figures 7-9. In the $\mathrm{Na}_{4} \mathrm{Cl}_{2}(\mathrm{OH})$ cluster, one of the excess electrons of the parent $\mathrm{Na}_{4} \mathrm{Cl}_{2}$ cluster localizes on the hydroxyl forming an $\mathrm{OH}^{-}$anion, while the other one localizes 


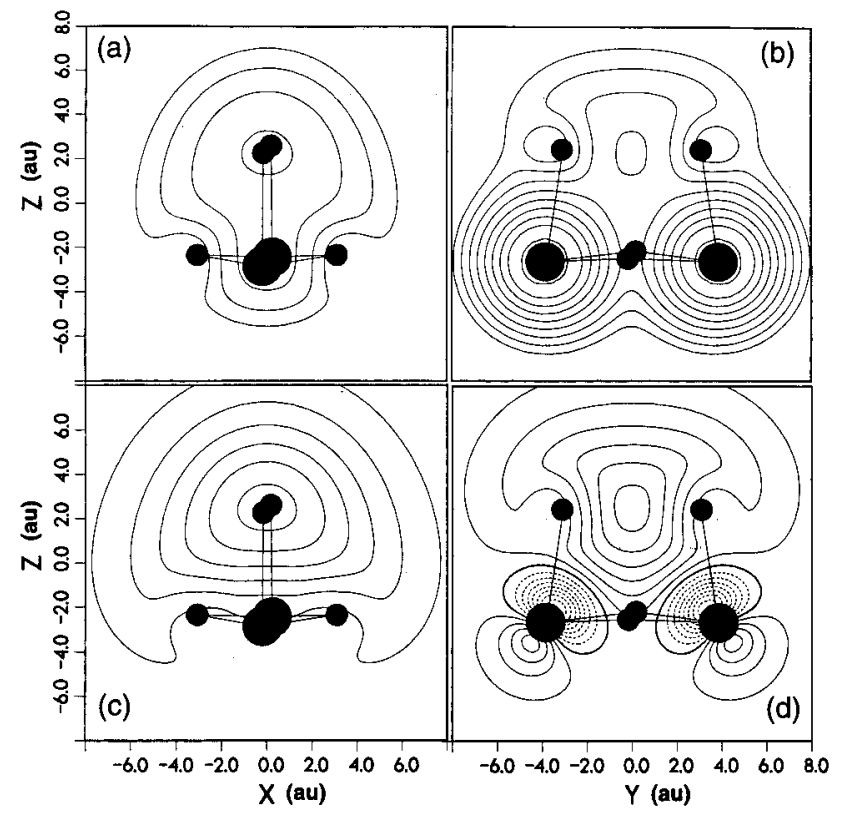

Figure 4. Same as Figure 3, but for the $\mathrm{Na}_{4} \mathrm{Cl}_{2}$ cluster. In this case the $\mathrm{KS}-\mathrm{HOMO}$ orbital is occupied by two excess electrons.

at the missing halogen vacancy (see Figure 8), and the electronic charge distributions, as well as the $\mathrm{HOMO}$ wave function, are very similar to those of the undoped $\mathrm{Na}_{4} \mathrm{Cl}_{3}$ cluster. This is reflected in the Kohn-Sham (KS) energy level scheme dis-

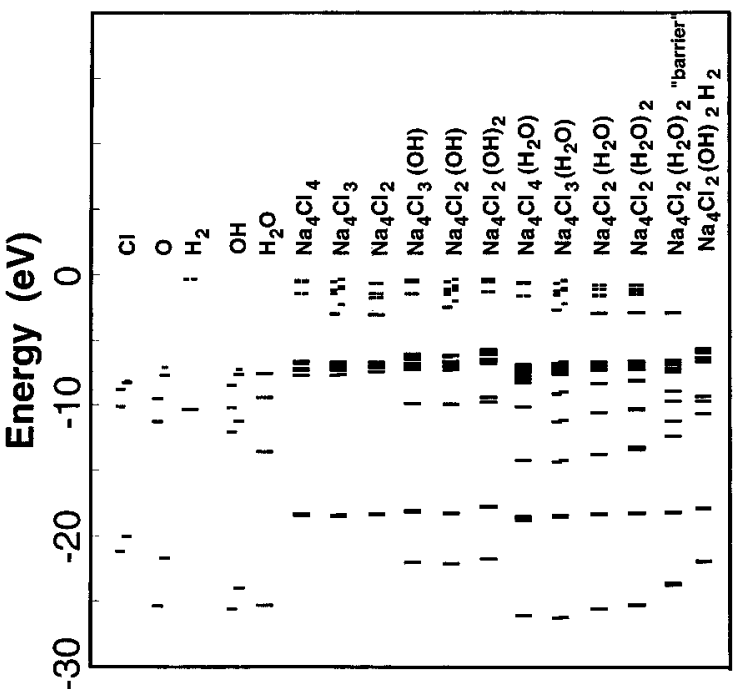

Figure 5. LSD Kohn-Sham energy levels for the indicated systems. For each species, levels for both spin orientations are shown, with upspin on the left and down-spin on the right (when these are degenerate a long horizontal line is drawn). The shortest lines correspond to unoccupied levels and the longer ones to occupied levels.

played in Figure 5, where the one for the $\mathrm{Na}_{4} \mathrm{Cl}_{3}$ cluster is seen to be similar to that of $\mathrm{Na}_{4} \mathrm{Cl}_{2} \mathrm{OH}$; note in particular the position of the excess electron level (the highest occupied molecular orbital, HOMO), which in both cases is "split off" from the

TABLE 1: Interatomic Bond Distances (in Å) Specifying the Optimal Structures Shown in Figures 1, 6, 10, 14, and 16 ${ }^{a}$

\begin{tabular}{|c|c|c|c|c|c|c|c|c|c|c|c|c|c|}
\hline \multirow[b]{2}{*}{ bond } & \multicolumn{13}{|c|}{ figure } \\
\hline & $1 \mathrm{a}$ & $1 b$ & $1 \mathrm{c}$ & $6 a$ & $6 b$ & $6 c$ & $10 \mathrm{a}$ & $10 \mathrm{~b}$ & $10 \mathrm{c}$ & $10 \mathrm{~d}$ & 14 & $16 \mathrm{a}$ & $16 \mathrm{~b}$ \\
\hline$(1-2)$ & 3.466 & 3.466 & 3.269 & 3.501 & 3.428 & 3.450 & 4.010 & 3.417 & 3.303 & 3.431 & 3.380 & 3.106 & \\
\hline$(1-3)$ & 2.641 & 2.640 & 2.622 & 2.667 & 2.616 & 2.668 & 2.658 & 2.648 & 2.621 & 2.678 & 2.671 & 3.159 & \\
\hline$(1-5)$ & 3.466 & 3.467 & 3.435 & 3.201 & 3.921 & 3.222 & 4.046 & 3.483 & 3.478 & 3.646 & 3.414 & & \\
\hline$(1-7)$ & 4.554 & 4.554 & & 4.457 & 4.433 & 4.064 & 4.773 & 4.308 & 4.323 & 4.437 & 4.065 & 3.303 & \\
\hline$(1-8)$ & 2.641 & & & 2.248 & 5.348 & 2.249 & 2.642 & 2.454 & 5.233 & 2.329 & 2.266 & 2.255 & \\
\hline$(1-9)$ & & & & 2.970 & & 5.015 & 6.064 & 3.345 & 3.827 & 2.771 & 3.236 & 2.561 & \\
\hline$(1-10)$ & & & & & & 2.854 & 5.675 & 2.885 & & 3.213 & 3.018 & 3.143 & \\
\hline$(2-3)$ & 2.641 & 2.641 & 2.622 & 2.661 & 2.683 & 2.668 & 2.671 & 2.656 & 2.660 & 2.678 & 2.671 & 3.461 & \\
\hline$(2-5)$ & 3.466 & 3.466 & 3.435 & 3.439 & 3.194 & 3.222 & 4.062 & 3.512 & 3.589 & 3.646 & 3.414 & & \\
\hline$(2-7)$ & 2.641 & 2.641 & & 2.662 & 2.227 & 2.249 & 2.627 & 2.678 & 2.312 & 2.329 & 2.266 & 3.983 & \\
\hline$(2-8)$ & 4.554 & & & 4.170 & 2.948 & 4.064 & 4.601 & 4.200 & 3.200 & 4.437 & 4.065 & 4.827 & \\
\hline$(2-9)$ & & & & 5.112 & & 2.854 & 4.925 & 4.416 & 2.718 & 3.959 & 3.848 & 4.512 & \\
\hline$(2-10)$ & & & & & & 5.015 & 4.926 & 5.129 & & 5.347 & 5.009 & 5.773 & \\
\hline$(3-4)$ & 3.970 & 3.970 & 4.087 & 3.960 & 4.042 & 3.996 & 3.471 & 4.005 & 4.071 & 4.082 & 4.062 & 1.512 & 3.381 \\
\hline$(3-5)$ & 2.641 & 2.641 & 2.728 & 2.647 & 2.678 & 2.681 & 3.422 & 2.621 & 2.678 & 2.665 & 2.624 & & \\
\hline$(3-7)$ & 3.971 & 3.970 & & 4.026 & 3.691 & 3.699 & 3.542 & 3.977 & 3.888 & 3.872 & 3.745 & 0.970 & 2.342 \\
\hline$(3-8)$ & 3.971 & & & 3.703 & 4.525 & 3.699 & 3.422 & 3.819 & 4.737 & 3.872 & 3.745 & 2.899 & 2.342 \\
\hline$(3-9)$ & & & & 4.516 & & 4.466 & 5.197 & 4.320 & 3.781 & 3.784 & 4.056 & 2.059 & 2.540 \\
\hline$(3-10)$ & & & & & & 4.466 & 4.705 & 4.499 & & 4.720 & 4.563 & 3.568 & 3.077 \\
\hline$(5-6)$ & 3.466 & 3.468 & 3.285 & 3.298 & 3.421 & 3.053 & 3.926 & 4.018 & 4.091 & 4.256 & 3.907 & & \\
\hline$(5-7)$ & 2.641 & 2.640 & & 2.658 & 2.208 & 2.257 & 2.816 & 2.657 & 2.961 & 2.977 & 2.580 & & \\
\hline$(5-8)$ & 2.641 & & & 2.254 & 2.813 & 2.257 & 2.648 & 2.617 & 3.471 & 2.977 & 2.580 & & \\
\hline$(5-9)$ & & & & 2.851 & & 2.943 & 3.202 & 2.543 & 2.400 & 2.445 & 2.217 & & \\
\hline$(5-10)$ & & & & & & 2.943 & 2.410 & 3.316 & & 3.470 & 3.148 & & \\
\hline$(7-8)$ & 3.970 & & & 3.611 & 0.953 & 3.324 & 3.750 & 3.372 & 0.965 & 4.158 & 3.370 & 2.572 & 2.530 \\
\hline$(7-9)$ & & & & 4.304 & & 0.952 & 2.317 & 2.951 & 0.996 & 3.271 & 2.460 & 1.607 & 1.964 \\
\hline$(7-10)$ & & & & & & 4.158 & 2.473 & 4.298 & & 4.803 & 4.106 & 3.142 & 3.441 \\
\hline$(8-9)$ & & & & 0.952 & & 4.158 & 4.032 & 0.981 & 1.548 & 1.003 & 1.312 & 0.991 & 1.095 \\
\hline$(8-10)$ & & & & & & 0.952 & 3.567 & 0.974 & & 0.966 & 0.958 & 0.951 & 0.971 \\
\hline$(9-10)$ & & & & & & 4.928 & 0.965 & 1.527 & & 1.538 & 1.726 & 1.576 & 1.681 \\
\hline
\end{tabular}

${ }^{a}$ The atoms $(\mathrm{i}-\mathrm{j})$ defining the bonds are numbered as in the corresponding figures. All the structures in these figures contain a mirror reflection plane passing through the set of atoms (or a subset of these atoms) numbered 1,2, 7, 8, 9, and also 10, 11, and 12 (except in Figure 10a where the mirror plane passes through atoms numbered 1,2,7,8, and 9, bisecting the angle between the two OH bonds; this mirror plane is perpendicular to the bond vectors connecting atoms $(3,4)$ and $(5,6)$ when they are present. Together with this mirror reflection symmetry, the distances which are given specify completely the corresponding structures. The bond distances are given to three significant figures since in some cases this is necessary in order to compare variations of certain bond distances from one structure to another. However, computational uncertainties (e.g., associated with the use of a finite grid) limit the estimated accuracy to two significant figures (i.e., rounding-off the third figure after the decimal point to the nearest digit). 

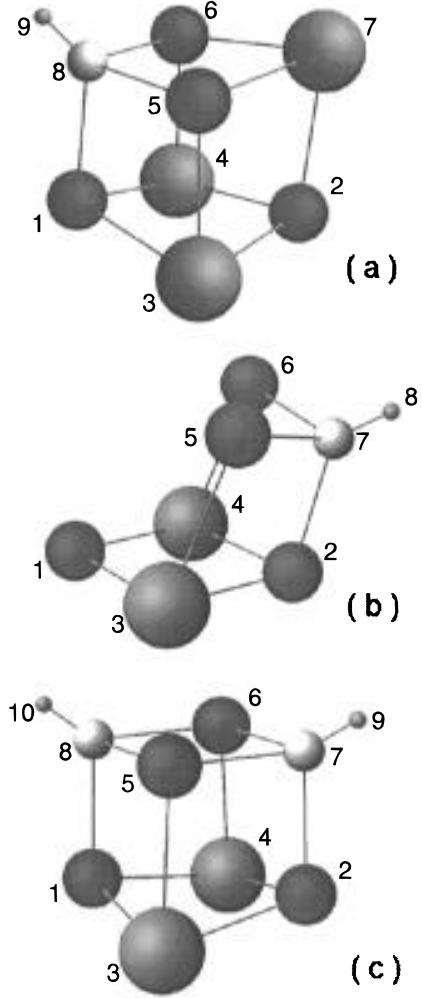

Figure 6. Optimal geometries for $\mathrm{OH}$-doped clusters $\mathrm{Na}_{4} \mathrm{Cl}_{3}(\mathrm{OH}), \mathrm{Na}_{4}-$ $\mathrm{Cl}_{2}(\mathrm{OH})$, and $\mathrm{Na}_{4} \mathrm{Cl}_{2}(\mathrm{OH})_{2}$, in (a), (b), and (c), respectively. Large and medium dark spheres represent chlorine and sodium atoms (in ratio of their ionic radii), and light smaller spheres represent oxygen and hydrogen (the smallest size) atoms. The distance $d_{\mathrm{OH}} \simeq 0.95 \AA$ in the hydroxyl ion and the $\mathrm{OH}$ bond is oriented close to the $\langle 111\rangle$ direction of the approximate cuboid structure.

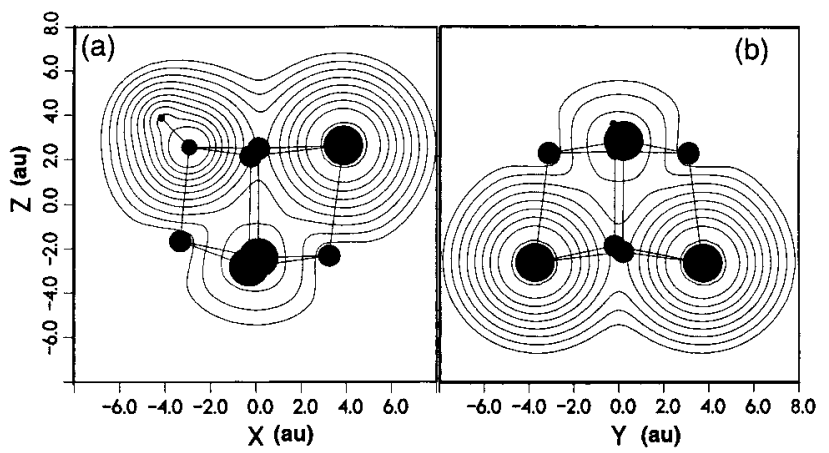

Figure 7. Optimal structure and superimposed contours of the total electronic charge density for $\mathrm{Na}_{4} \mathrm{Cl}_{3} \mathrm{OH}$, plotted in two orthogonal planes of the structure (the one shown in a contains the $\mathrm{OH}$ bond); see caption of Figure 3 for contour values.

bottom of the manifold of unoccupied states, characteristic to F-center electrons in alkali halides. ${ }^{17-20}$ On the other hand, in clusters with no remaining "free" excess electrons (i.e., $\mathrm{Na}_{4}-$ $\mathrm{Cl}_{3}(\mathrm{OH})$ and $\mathrm{Na}_{4} \mathrm{Cl}_{2}(\mathrm{OH})_{2}$, where the excess electron(s) are bound to the hydroxyl anion(s)) that level does not appear due to formation of the $\mathrm{OH}^{-}$ion(s); note also the appearance of $\mathrm{OH}$-derived levels in the $\mathrm{s}-\mathrm{p}$ gap of the doped clusters. This is also reflected in the electronic density contours of these clusters (Figures 7 and 9) which are similar to those of the corresponding undoped stoichiometric $\mathrm{Na}_{4} \mathrm{Cl}_{4}$ cluster (Figure 2).

It is instructive to observe that while formation of an F-center defect is accompanied by a large decrease in the vertical and adiabatic ionization potentials (vIP and aIP), respectively (compare values for $\mathrm{Na}_{4} \mathrm{Cl}_{4}$ and $\mathrm{Na}_{4} \mathrm{Cl}_{3}$ in Table 2), doping the nonstoichiometric clusters with a hydroxyl group, particularly when no free excess electrons remain, restores the ionization

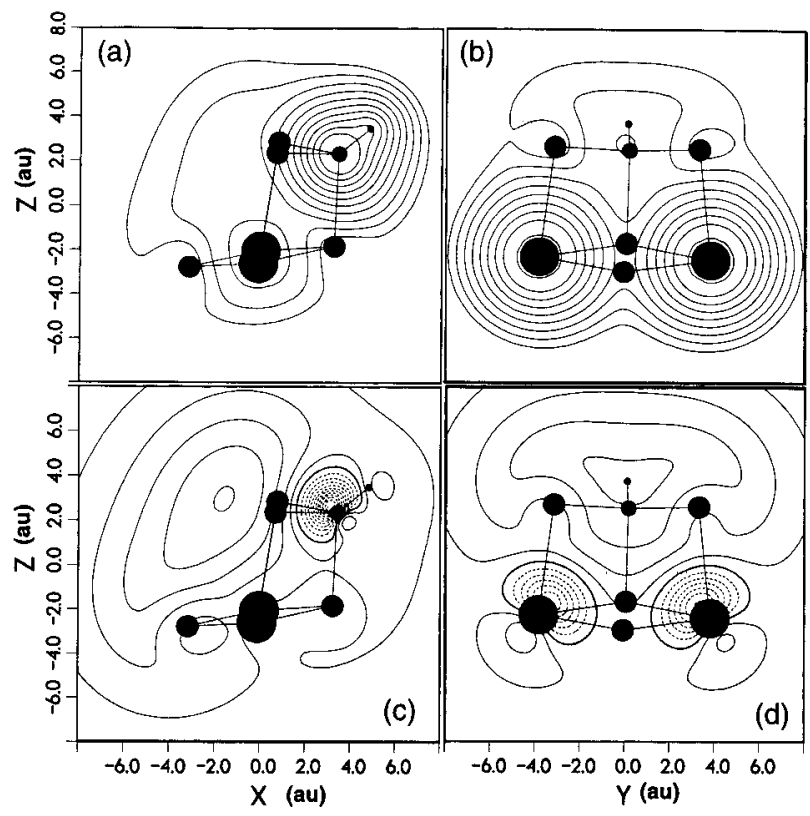

Figure 8. Optimal structure of $\mathrm{Na}_{4} \mathrm{Cl}_{2}(\mathrm{OH})$ and superimposed contours of the total electronic charge density ( $a, b)$, and contours of the highest occupied KS-HOMO wave function occupied by the excess electron (c, d). (Solid and dashed lines correspond to positive and negative values of the wave function, respectively.) For both, contours are plotted in two orthogonal planes through the cluster, with the one in (a) and (c) containing the $\mathrm{OH}$ bond. Note preferential localization of the excess electron in the vacant F-center site, and partial mixing with the hydroxyl and chlorine anions' orbitals (see c and d). See caption of Figure 3 for contour values.

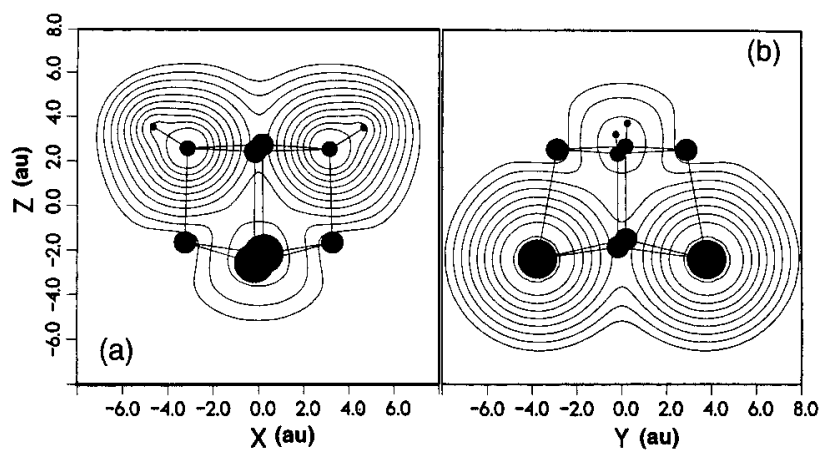

Figure 9. Same as Figure 7, but for the $\mathrm{Na}_{4} \mathrm{Cl}_{2}(\mathrm{OH})_{2}$ cluster.

potentials to the high values of the corresponding stoichiometric one (i.e., $\mathrm{Na}_{4} \mathrm{Cl}_{4}$ ); e.g., compare the ionization potential values (Table 2) for $\mathrm{Na}_{4} \mathrm{Cl}_{3}(\mathrm{OH})$ and $\mathrm{Na}_{4} \mathrm{Cl}_{2}(\mathrm{OH})_{2}$ with those of $\mathrm{Na}_{4}$ $\mathrm{Cl}_{4}$. On the other hand, while the vIPs for $\mathrm{Na}_{4} \mathrm{Cl}_{3}$ (containing a single F-center excess electron, vIP $=4.925 \mathrm{eV}$ ) and $\mathrm{Na}_{4} \mathrm{Cl}_{2}$ (containing two F-center excess electrons, vIP $=4.82 \mathrm{eV}$ ) are close, that for the $\mathrm{Na}_{4} \mathrm{Cl}_{2}(\mathrm{OH})$-doped cluster (containing one free excess electron) is lower (vIP $=4.16 \mathrm{eV}$ ).

The energetics displayed in Table 2 reflects the effectiveness of substitution of a halide by a hydroxyl. For example, the chlorine removal energy for $\mathrm{Na}_{4} \mathrm{Cl}_{4}$ is essentially the same as that for $\mathrm{Na}_{4} \mathrm{Cl}_{3}(\mathrm{OH})$, and the energy to remove the dopant $(\mathrm{OH})$ group from the latter is only $\sim 0.3 \mathrm{eV}$ smaller than that needed to remove a $\mathrm{Cl}$ atom.

These results lead us to conclude that energetically and structurally the series of $\mathrm{OH}$-doped nonstoichiometric sodium chloride clusters (e.g., $\mathrm{Na}_{4} \mathrm{Cl}_{4-m}(\mathrm{OH})_{l} ; m=1,2,1 \leq l \leq m$ ) is similar to the corresponding series of undoped cluster $\mathrm{Na}_{4} \mathrm{Cl}_{4-m+l}$. That is, the couples $\mathrm{Na}_{4} \mathrm{Cl}_{4}$ and $\mathrm{Na}_{4} \mathrm{Cl}_{3}(\mathrm{OH}) ; \mathrm{Na}_{4} \mathrm{Cl}_{4}$ and $\mathrm{Na}_{4}-$ $\mathrm{Cl}_{2}(\mathrm{OH})_{2}$; and $\mathrm{Na}_{4} \mathrm{Cl}_{3}$ and $\mathrm{Na}_{4} \mathrm{Cl}_{2}(\mathrm{OH})$, may be regarded as homologous. 
TABLE 2: Energetics of Small Sodium Chloride Clusters, OH-Doped Nonstoichiometric Clusters, and Water Adsorption on Sodium Chloride Clusters ${ }^{a}$

\begin{tabular}{|c|c|c|c|c|c|c|c|c|c|c|}
\hline & \multicolumn{2}{|c|}{$\Delta(\mathrm{Cl})$} & \multicolumn{2}{|c|}{$\Delta(\mathrm{OH})$} & \multicolumn{2}{|c|}{$\Delta\left(\mathrm{H}_{2} \mathrm{O}\right)$} & \multicolumn{2}{|c|}{ vIP } & \multicolumn{2}{|c|}{ aIP } \\
\hline & LSD & PLSD & LSD & PLSD & LSD & PLSD & LSD & PLSD & LSD & PLSD \\
\hline $\mathrm{Na}_{4} \mathrm{Cl}_{4}$ & 5.94 & 5.54 & & & & & 9.19 & 9.165 & 8.75 & 8.865 \\
\hline $\mathrm{Na}_{4} \mathrm{Cl}_{3}$ & 5.295 & 4.985 & & & & & 4.86 & 4.925 & 3.94 & 4.03 \\
\hline $\mathrm{Na}_{4} \mathrm{Cl}_{2}$ & & & & & & & 4.88 & 4.82 & 4.51 & 4.5 \\
\hline $\mathrm{Na}_{4} \mathrm{Cl}_{3}(\mathrm{OH})$ & 5.935 & 5.57 & 5.78 & 5.25 & & & $8.64^{b}$ & $8.58^{b}$ & & \\
\hline $\mathrm{Na}_{4} \mathrm{Cl}_{2}(\mathrm{OH})$ & & & 5.14 & 4.66 & & & 4.22 & 4.16 & 3.78 & 3.81 \\
\hline $\mathrm{Na}_{4} \mathrm{Cl}_{2}(\mathrm{OH})_{2}$ & & & 5.77 & 5.27 & & & $8.46^{b}$ & $8.13^{b}$ & & \\
\hline $\mathrm{Na}_{4} \mathrm{Cl}_{4}\left(\mathrm{H}_{2} \mathrm{O}\right)$ & 6.04 & 5.71 & & & 0.74 & 0.49 & & & & \\
\hline $\mathrm{Na}_{4} \mathrm{Cl}_{3}\left(\mathrm{H}_{2} \mathrm{O}\right)$ & 5.165 & 4.98 & & & 0.64 & 0.32 & 4.45 & 4.38 & 3.755 & 3.81 \\
\hline $\mathrm{Na}_{4} \mathrm{Cl}_{2}\left(\mathrm{H}_{2} \mathrm{O}\right)$ & & & & & 0.77 & 0.33 & 4.72 & 4.60 & 4.39 & 4.31 \\
\hline $\mathrm{Na}_{4} \mathrm{Cl}_{2}\left(\mathrm{H}_{2} \mathrm{O}\right)_{2}$ & & & & & 0.60 & 0.49 & 4.67 & 4.48 & 4.43 & 4.28 \\
\hline \multirow[t]{2}{*}{$\mathrm{NaCl}$} & 4.43 & 4.10 & & & & & & & & \\
\hline & $5.66^{c}$ & $5.26^{c}$ & & & & & & & & \\
\hline \multirow[t]{2}{*}{$\mathrm{NaCl}\left(\mathrm{H}_{2} \mathrm{O}\right)$} & 5.04 & 4.56 & & & 1.01 & 0.76 & & & & \\
\hline & $5.62^{d}$ & $5.535^{d}$ & & & & & & & & \\
\hline
\end{tabular}

${ }^{a}$ Results (in units of eV) from LSD and PLSD calculations are given for ground state reactions and products. $\Delta(\mathrm{Cl}), \Delta(\mathrm{OH})$, and $\Delta\left(\mathrm{H}_{2} \mathrm{O}\right)$ are the energies required to remove (i.e., difference between the total energies of the products and the reactants) a $\mathrm{Cl}$ atom, an $\mathrm{OH}^{-}$, or a water molecule; respectively. vIP and aIP are the vertical and adiabatic ionization potentials, respectively. ${ }^{b}$ Fractional occupation encountered. ${ }^{c}$ The energetics of $\mathrm{NaCl} \rightarrow \mathrm{Na}^{+}+\mathrm{Cl}^{-}$. ${ }^{d}$ The energetics of $\mathrm{NaCl}\left(\mathrm{H}_{2} \mathrm{O}\right) \rightarrow \mathrm{Na}^{+}\left(\mathrm{H}_{2} \mathrm{O}\right)+\mathrm{Cl}^{-}$.
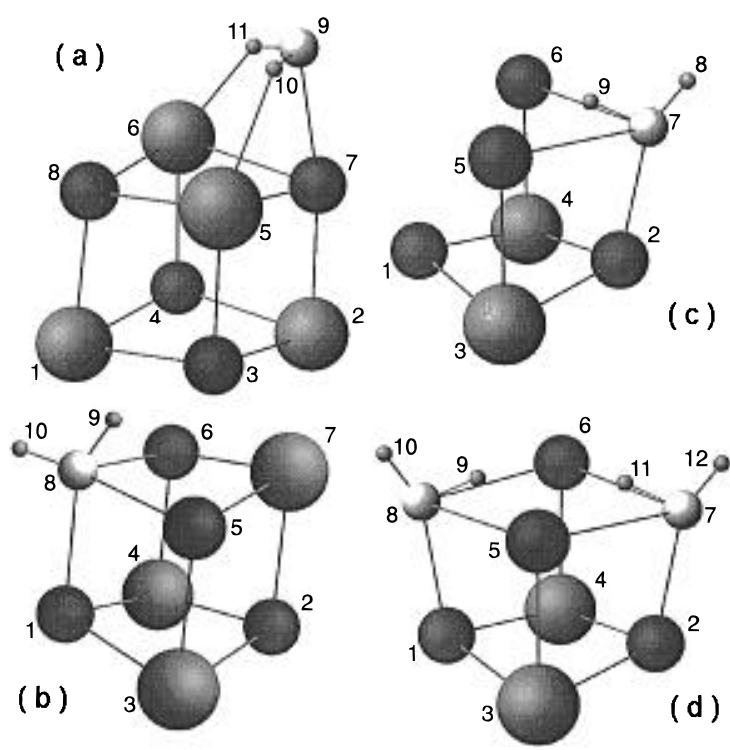

Figure 10. Optimal structures of hydrated clusters, $\mathrm{Na}_{4} \mathrm{Cl}_{4}\left(\mathrm{H}_{2} \mathrm{O}\right), \mathrm{Na}_{4}-$ $\mathrm{Cl}_{3}\left(\mathrm{H}_{2} \mathrm{O}\right), \mathrm{Na}_{4} \mathrm{Cl}_{2}\left(\mathrm{H}_{2} \mathrm{O}\right)$, and $\mathrm{Na}_{4} \mathrm{Cl}_{2}\left(\mathrm{H}_{2} \mathrm{O}\right)_{2}$, in $(\mathrm{a}-\mathrm{d})$, respectively. In $\mathrm{Na}_{4} \mathrm{Cl}_{4}\left(\mathrm{H}_{2} \mathrm{O}\right)$ the distances between the oxygen atom and the nearest sodium and chlorine ions are $d_{\mathrm{Na}-\mathrm{O}}=2.32 \AA$ and $d_{\mathrm{Cl}-\mathrm{O}}=3.20 \AA, d_{\mathrm{OH}}$ $=0.965 \AA, \angle \mathrm{HOH}=104.8^{\circ}$, and the molecular plane of the $\mathrm{H}_{2} \mathrm{O}$ molecule is tilted by $13^{\circ}$ (toward the chlorines) with respect to the top plane of the approximate cuboid structure of the alkali halide cluster. For $\mathrm{Na}_{4} \mathrm{Cl}_{3}\left(\mathrm{H}_{2} \mathrm{O}\right)$, the distance of the oxygen to the closest sodium ion is $d_{\mathrm{Na}-\mathrm{O}}=2.45 \AA$, and that to the two next-nearest sodiums is $d_{\mathrm{Na}-\mathrm{O}}$ $=2.62 \AA$. The intermolecular $\mathrm{OH}$ distance $d_{\mathrm{OH}}=0.98 \AA, \angle \mathrm{HOH}=$ $102.5^{\circ}$, and the angle between the bisector of the $\mathrm{HOH}$ angle and the top plane of the sodium cluster is $\beta=102^{\circ}$. In $\mathrm{Na}_{4} \mathrm{Cl}_{2}\left(\mathrm{H}_{2} \mathrm{O}\right) \beta=74^{\circ}$, and in $\mathrm{Na}_{4} \mathrm{Cl}_{2}\left(\mathrm{H}_{2} \mathrm{O}\right)_{2} \beta=83^{\circ}$. In $\mathrm{Na}_{4} \mathrm{Cl}_{2}\left(\mathrm{H}_{2} \mathrm{O}\right)_{2}$ the intermolecular distance between the two closest hydrogens is $2.331 \AA$.

(b) Water Adsorption: $\mathrm{Na}_{4} \mathrm{Cl}_{m}\left(\mathrm{H}_{2} \mathrm{O}\right) m=\mathbf{2 , 3 , 4}$, and $\mathrm{Na}_{4}-$ $\mathbf{C l}_{\mathbf{2}}\left(\mathbf{H}_{2} \mathbf{O}\right)_{2}$. In Figure 10 and Table 2 we display the optimal geometries (values of the geometrical parameters corresponding to the structures shown in Figure 10 are given in Table 1) and energetics of water molecules adsorbed on stoichiometric $\left(\mathrm{Na}_{4}-\right.$ $\mathrm{Cl}_{4}\left(\mathrm{H}_{2} \mathrm{O}\right)$, Figure 10a) and nonstoichiometric $\left(\mathrm{Na}_{4} \mathrm{Cl}_{3}\left(\mathrm{H}_{2} \mathrm{O}\right)\right.$, Figure 10b; $\mathrm{Na}_{4} \mathrm{Cl}_{2}\left(\mathrm{H}_{2} \mathrm{O}\right)$, Figure 10c; and $\mathrm{Na}_{4} \mathrm{Cl}_{2}\left(\mathrm{H}_{2} \mathrm{O}\right)_{2}$, Figure $10 \mathrm{~d})$ clusters. The corresponding KS levels are given in Figure 5.

The PLSD calculated binding energy of $\mathrm{H}_{2} \mathrm{O}$ to the $\mathrm{Na}_{4} \mathrm{Cl}_{4}$ cluster is $0.49 \mathrm{eV}$, compared to an energy of $0.76 \mathrm{eV}$ binding $\mathrm{H}_{2} \mathrm{O}$ to an $\mathrm{NaCl}$ molecule. In the optimal geometry of $\mathrm{Na}_{4}-$
$\mathrm{Cl}_{4}\left(\mathrm{H}_{2} \mathrm{O}\right)$ the oxygen atom is located a distance of $2.317 \AA$ from the nearest sodium cation and is shifted by $0.374 \AA$ along the $\mathrm{Na}^{+}-\mathrm{Na}^{+}$axis from the "on-top" position above a corner sodium cation, with the molecular plane tilted by $13.2^{\circ}$ toward the chlorine anions with respect to the "(100) facet" of the cluster (see Figure 10a). The calculated binding energy is in the range estimated in recent experiments of water adsorption on the $\mathrm{NaCl}-$ (100) surface (see Table 2 in ref 10 , where a value of $\sim 0.65$ $\mathrm{eV}$ is given along with other estimates ranging from 0.36 to 0.68 , and $0.46 \mathrm{eV}^{33}$ ). The calculated optimal geometry of the molecule is also in agreement with that described in ref 10 for a single water molecule adsorbed on the $\mathrm{NaCl}$ (100) surface, where the molecular plane was found to be nearly parallel to the (100) face of the crystalline surface.

It has been suggested that $\mathrm{F}$ centers may act as defect centers for chemical activity on $\mathrm{NaCl}$ surfaces, ${ }^{34}$ e.g., light-induced $\mathrm{H}$ and $\mathrm{F}$ centers in $\mathrm{NaCl}$ have been proposed as inducing bondbreaking reactions of $\mathrm{C}_{2} \mathrm{H}_{2} \cdot{ }^{35}$ Consequently, we discuss in the following the adsorption of water molecules on nonstoichiometric sodium chloride clusters (i.e., finite F-center systems). The optimal structures for $\mathrm{Na}_{4} \mathrm{Cl}_{3}\left(\mathrm{H}_{2} \mathrm{O}\right)$, and $\mathrm{Na}_{4} \mathrm{Cl}_{2}\left(\mathrm{H}_{2} \mathrm{O}\right)_{2}$ (Figures $10 \mathrm{~b}-\mathrm{d}$ ) and the corresponding electron density and wave function contours shown in Figures 11-13, together with the KS level schemes given in Figure 5, reveal the following:

(i) A water molecule adsorbs at the site of a missing halogen, and its orientation differs from that of $\mathrm{H}_{2} \mathrm{O}$ adsorbed on the stoichiometric cluster (compare Figure 10b-d with Figure 10a).

(ii) In $\mathrm{Na}_{4} \mathrm{Cl}_{3}\left(\mathrm{H}_{2} \mathrm{O}\right)$ the excess electron $\mathrm{KS}$ level is located very close to its value in $\mathrm{Na}_{4} \mathrm{Cl}_{3}$ (Figure 5). However, while in $\mathrm{Na}_{4} \mathrm{Cl}_{3}$ the excess electron is well localized about the site of the missing halogen (playing essentially a substitutional role), the probability density distribution of the excess electron is more diffuse in the hydrated cluster, due to the lack of affinity of the close-shell $\mathrm{H}_{2} \mathrm{O}$ molecule to bind an electron (Figure 11), although some degree of localization of the excess electron near the hydrogens is observed (see Figure 11c where the HOMO$\mathrm{KS}$ wave function is shown). Consequently, the excess electron is partially expelled from the F-center site which becomes occupied by the $\mathrm{H}_{2} \mathrm{O}$ molecule. This effect is correlated with a decrease in the vertical and adiabatic ionization potentials upon $\mathrm{H}_{2} \mathrm{O}$ adsorption to the $\mathrm{Na}_{4} \mathrm{Cl}_{3}$ cluster (see Table 2).

(iii) Adsorption of a single $\mathrm{H}_{2} \mathrm{O}$ molecule to the $\mathrm{Na}_{4} \mathrm{Cl}_{2}$ cluster (containing two excess electrons), distorts the electron density distribution of the doubly-occupied (spin-paired) excess-electron 


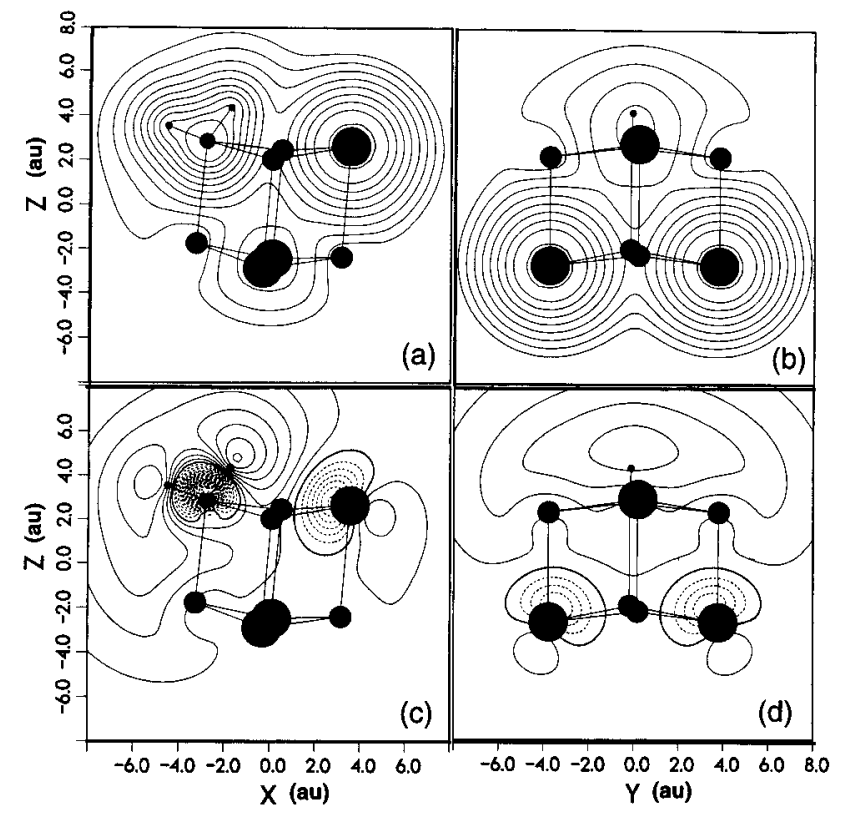

Figure 11. Optimal structure of the hydrated $\mathrm{Na}_{4} \mathrm{Cl}_{3}\left(\mathrm{H}_{2} \mathrm{O}\right)$ cluster, and superimposed contours of the total electronic charge density $(\mathrm{a}, \mathrm{b})$, and KS-HOMO wave function occupied by the excess electron (c, d). For both, contours are plotted in two orthogonal planes through the cluster, with the one in (a) and (c) containing the molecular plane of the $\mathrm{H}_{2} \mathrm{O}$ molecule. Note expulsion of the excess electron from the F-center site, and partial mixing with the $\mathrm{H}_{2} \mathrm{O}$ and chlorine anions' orbitals.

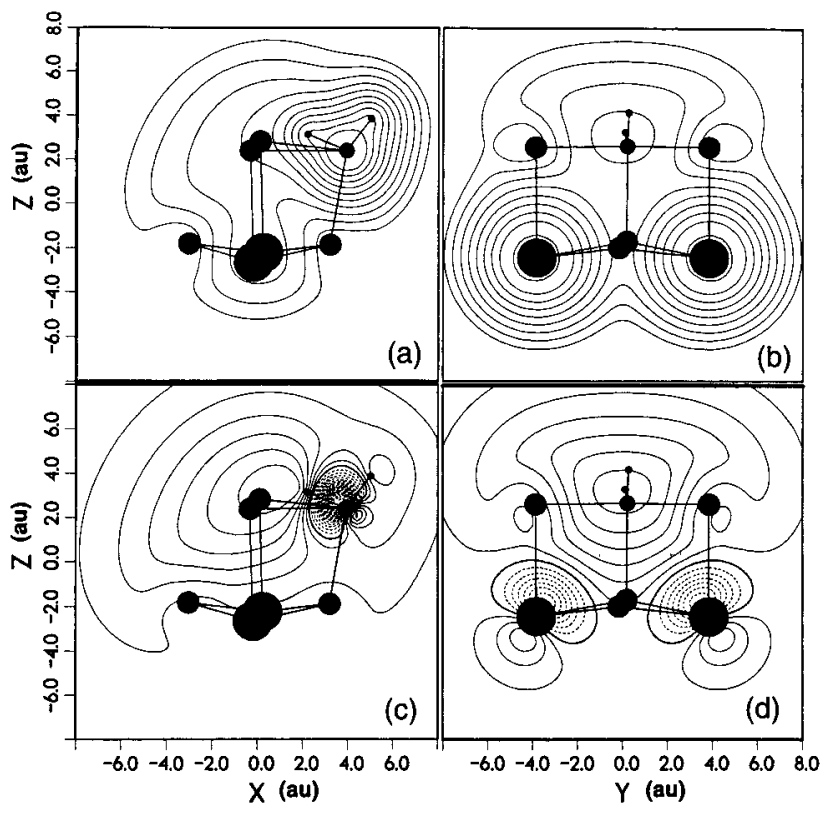

Figure 12. Same as Figure 11 but for $\mathrm{Na}_{4} \mathrm{Cl}_{2}\left(\mathrm{H}_{2} \mathrm{O}\right)$.

molecular orbital (Figure 12 with Figure 4), while the location of the corresponding KS eigenvalue is essentially the same as in the parent unsolvated $\mathrm{Na}_{4} \mathrm{Cl}_{2}$ cluster (Figure 5). The ionization potentials of the solvated cluster $\left(\mathrm{Na}_{4} \mathrm{Cl}_{2}\left(\mathrm{H}_{2} \mathrm{O}\right)\right)$ are about $0.2 \mathrm{eV}$ lower than those of the unsolvated one.

(iv) The KS energy level scheme for the $\mathrm{Na}_{4} \mathrm{Cl}_{2}$ cluster solvated by the adsorption of two $\mathrm{H}_{2} \mathrm{O}$ molecules (i.e., $\mathrm{Na}_{4}-$ $\left.\mathrm{Cl}_{2}\left(\mathrm{H}_{2} \mathrm{O}\right)_{2}\right)$ is essentially the same as that of the $\mathrm{Na}_{4} \mathrm{Cl}_{2}\left(\mathrm{H}_{2} \mathrm{O}\right)$ and $\mathrm{Na}_{4} \mathrm{Cl}_{2}$ clusters. However, the two excess electron orbital (HOMO) in $\mathrm{Na}_{4} \mathrm{Cl}_{2}\left(\mathrm{H}_{2} \mathrm{O}\right)_{2}$ is distorted significantly from that in the unsolvated and singly-solvated clusters (compare Figure 13 with Figures 4 and 12; note particularly the contours in the plane of the two adsorbed $\mathrm{H}_{2} \mathrm{O}$ molecules, displayed in Figure

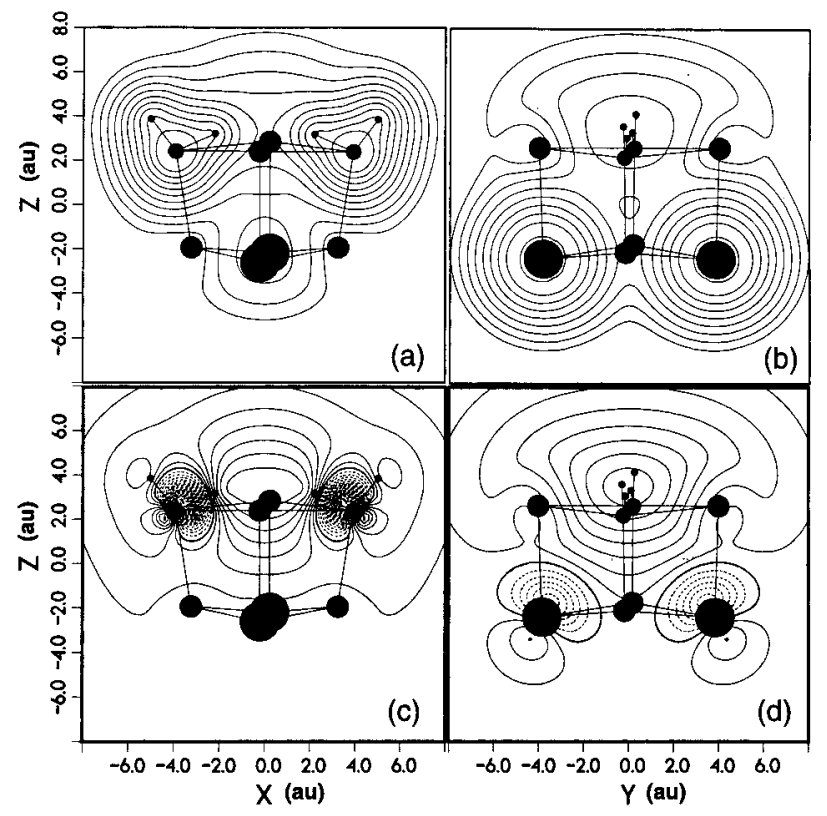

Figure 13. Same as Figure 11 but for $\mathrm{Na}_{4} \mathrm{Cl}_{2}\left(\mathrm{H}_{2} \mathrm{O}\right)_{2}$. Note preferential concentration of the excess electrons in the region between the two water molecules (see in particular the contours of the KS-HOMO wave function occupied by the two excess electrons, shown in (c) and (d)).

13, where a marked localization of the two excess electrons in the regions between the two water molecules is observed). Further decrease in the vertical ionization potential, as compared to the singly-solvated cluster, is predicted (see Table 2). The binding energies of water molecules to the nonstoichiometric sodium cluster are in the range of $\sim 0.25-0.32 \mathrm{eV}$, reflecting the rather inert nature of the $\mathrm{H}_{2} \mathrm{O}$ molecule. Additionally, the $\mathrm{Cl}$ removal energy from $\mathrm{Na}_{4} \mathrm{Cl}_{3}(4.985 \mathrm{eV})$ is unaffected by adsorption of a water molecule.

(c) Reactions. From our calculations the energies of several reactions of water with stoichiometric and nonstoichiometric clusters can be obtained:

(i) The first set of reactions which we consider are the hydrolysis reactions. These reactions are endothermic, with the following calculated energies (where $\Delta$ corresponds to the two reactants before association and $\Delta^{\prime}$ to the reaction energy starting from the associated reactants, e.g., $\mathrm{Na}_{4} \mathrm{Cl}_{4}\left(\mathrm{H}_{2} \mathrm{O}\right)$ for (a) below):

(a) $\mathrm{Na}_{4} \mathrm{Cl}_{4}+\mathrm{H}_{2} \mathrm{O} \rightarrow \mathrm{Na}_{4} \mathrm{Cl}_{3}(\mathrm{OH})+\mathrm{HCl}$

$$
\begin{array}{rlrl}
\Delta(\mathrm{LSD}) & =1.31 \mathrm{eV} & & \Delta(\mathrm{PLSD})=1.29 \mathrm{eV} \\
\Delta^{\prime}(\mathrm{LSD}) & =2.06 \mathrm{eV} & \Delta^{\prime}(\mathrm{PLSD})=1.78 \mathrm{eV}
\end{array}
$$

(b) $\mathrm{Na}_{4} \mathrm{Cl}_{4}+2 \mathrm{H}_{2} \mathrm{O} \rightarrow \mathrm{Na}_{4} \mathrm{Cl}_{2}(\mathrm{OH})_{2}+2 \mathrm{HCl}$

$$
\Delta(\mathrm{LSD})=2.64 \mathrm{eV} \quad \Delta(\mathrm{PLSD})=2.58 \mathrm{eV}
$$

(c) $\mathrm{Na}_{4} \mathrm{Cl}_{3}+\mathrm{H}_{2} \mathrm{O} \rightarrow \mathrm{Na}_{4} \mathrm{Cl}_{2}(\mathrm{OH})+\mathrm{HCl}$

$$
\begin{aligned}
\Delta(\mathrm{LSD}) & =1.31 \mathrm{eV} \quad \Delta(\mathrm{PLSD})=1.32 \mathrm{eV} \\
\Delta^{\prime}(\mathrm{LSD}) & =1.95 \mathrm{eV} \quad \Delta^{\prime}(\mathrm{PLSD})=1.64 \mathrm{eV} \\
(\mathrm{d}) \mathrm{Na}_{4} \mathrm{Cl}_{3} \mathrm{OH}+\mathrm{H}_{2} \mathrm{O} \rightarrow \mathrm{Na}_{4} \mathrm{Cl}_{2}(\mathrm{OH})_{2}+\mathrm{HCl} & \\
\Delta(\mathrm{LSD}) & =1.32 \mathrm{eV} \quad \Delta(\mathrm{PLSD})=1.30 \mathrm{eV}
\end{aligned}
$$

(e) $\mathrm{NaCl}+\mathrm{H}_{2} \mathrm{O} \rightarrow \mathrm{NaOH}+\mathrm{HCl}$

$$
\begin{aligned}
\Delta(\mathrm{LSD}) & =1.77 \mathrm{eV} & & \Delta(\mathrm{PLSD})=1.76 \mathrm{eV} \\
\Delta^{\prime}(\mathrm{LSD}) & =2.78 \mathrm{eV} & & \Delta^{\prime}(\mathrm{PLSD})=2.52 \mathrm{eV}
\end{aligned}
$$

(f) $(\mathrm{NaCl})_{2}+2 \mathrm{H}_{2} \mathrm{O} \rightarrow(\mathrm{NaOH})_{2}+2 \mathrm{HCl}$

$$
\Delta(\mathrm{LSD})=2.92 \mathrm{eV} \quad \Delta(\mathrm{PLSD})=2.89 \mathrm{eV}
$$


It is interesting to note that the calculated energies for cluster reactions $\mathrm{a}, \mathrm{b}$, and $\mathrm{d}$ are close to each other, and only about 0.1 $\mathrm{eV}$ smaller than the measured enthalpy of the hydrolysis reaction on an extended sodium chloride solid, i.e.,

$$
\mathrm{NaCl}(\mathrm{s})+\mathrm{H}_{2} \mathrm{O}(\mathrm{g}) \rightarrow \mathrm{NaOH}+\mathrm{HCl}(\mathrm{g})
$$

whose value is $1.4 \mathrm{eV} .{ }^{36} \mathrm{We}$ also remark that the energies for these reactions are smaller than that for an $\mathrm{NaCl}$ molecule by $\sim 0.4 \mathrm{eV}$.

(ii) The second set of processes which we consider are "etching" reactions, where a $\mathrm{Na}_{n} \mathrm{Cl}_{n}$ cluster is converted into a $\mathrm{Na}_{n-1} \mathrm{Cl}_{n-1}$ one.

(a) $\mathrm{Na}_{4} \mathrm{Cl}_{4}+\mathrm{H}_{2} \mathrm{O} \rightarrow \mathrm{Na}_{3} \mathrm{Cl}_{3}+\mathrm{NaOH}+\mathrm{HCl}$

$$
\begin{array}{rlrl}
\Delta(\mathrm{LSD}) & =4.23 \mathrm{eV} & & \Delta(\mathrm{PLSD})=3.93 \mathrm{eV} \\
\Delta^{\prime}(\mathrm{LSD}) & =4.97 \mathrm{eV} & \Delta^{\prime}(\text { PLSD })=4.42 \mathrm{eV}
\end{array}
$$

(b) $\mathrm{Na}_{3} \mathrm{Cl}_{3}+\mathrm{H}_{2} \mathrm{O} \rightarrow \mathrm{Na}_{2} \mathrm{Cl}_{2}+\mathrm{NaOH}+\mathrm{HCl}$

$$
\Delta(\mathrm{LSD})=3.42 \mathrm{eV} \quad \Delta(\mathrm{PLSD})=3.40 \mathrm{eV}
$$

(c) $\mathrm{Na}_{2} \mathrm{Cl}_{2}+\mathrm{H}_{2} \mathrm{O} \rightarrow \mathrm{NaCl}+\mathrm{NaOH}+\mathrm{HCl}$

$$
\Delta(\mathrm{LSD})=3.83 \mathrm{eV} \quad \Delta(\mathrm{PLSD})=3.74 \mathrm{eV}
$$

We note in this context that while the optimal structure of $\mathrm{Na}_{4} \mathrm{Cl}_{4}$ is a three-dimensional cuboid, those of $\mathrm{Na}_{3} \mathrm{Cl}_{3}$ and $\mathrm{Na}_{2}-$ $\mathrm{Cl}_{2}$ are two-dimensional (ring and rhombus, respectively). This correlates with the lower reaction energies for (b) and (c) compared to that in (a).

(iii) The last reaction which we consider is the $\mathrm{H}_{2}$ generation reaction, which is exothermic, i.e.,

(a) $\mathrm{Na}_{4} \mathrm{Cl}_{2}+2 \mathrm{H}_{2} \mathrm{O} \rightarrow \mathrm{Na}_{4} \mathrm{Cl}_{2}(\mathrm{OH})_{2}+\mathrm{H}_{2}$

$$
\Delta(\mathrm{LSD})=-3.225 \mathrm{eV} \quad \Delta(\mathrm{PLSD})=-3.45 \mathrm{eV}
$$

(a') $\mathrm{Na}_{4} \mathrm{Cl}_{2}\left(\mathrm{H}_{2} \mathrm{O}\right)_{2} \rightarrow \mathrm{Na}_{4} \mathrm{Cl}_{2}(\mathrm{OH})_{2}+\mathrm{H}_{2}$

$$
\Delta^{\prime}(\mathrm{LSD})=-1.855 \mathrm{eV} \quad \Delta^{\prime}(\mathrm{PLSD})=-2.63 \mathrm{eV}
$$

These reactions can be compared with those for $\mathrm{Na}_{2}$ dimer i.e.,

(b) $\mathrm{Na}_{2}+2 \mathrm{H}_{2} \mathrm{O} \rightarrow(\mathrm{NaOH})_{2}+\mathrm{H}_{2}$

$$
\Delta(\mathrm{LSD})=-1.81 \mathrm{eV} \quad \Delta(\mathrm{PLSD})=-2.0 \mathrm{eV}
$$

(b') $\mathrm{Na}_{2}\left(\mathrm{H}_{2} \mathrm{O}\right)_{2} \rightarrow(\mathrm{NaOH})_{2}+\mathrm{H}_{2}$

$$
\Delta^{\prime}(\mathrm{LSD})=-0.58 \mathrm{eV} \quad \Delta^{\prime}(\mathrm{PLSD})=-1.22 \mathrm{eV}
$$

We note the significantly larger exothermicity of the reactions involving the sodium chloride cluster ( $a$ and $a^{\prime}$ ). Moreover, the calculated reaction barrier for the $\left(a^{\prime}\right)$ reaction $\left(\Delta^{\prime}{ }_{b}(L S D)\right.$ $\left.=0.27 \mathrm{eV}, \Delta_{\mathrm{b}}^{\prime}(\mathrm{PLSD})=0.33 \mathrm{eV}\right)$ is much smaller than the one corresponding to the $\left(\mathrm{b}^{\prime}\right)$ reaction $\left(\Delta_{\mathrm{b}}^{\prime}(\mathrm{LSD})=1.28 \mathrm{eV}\right.$, $\left.\Delta^{\prime}{ }_{\mathrm{b}}(\mathrm{PLSD})=1.56 \mathrm{eV}\right)$. Using constrained minimization along the reaction path, where the ground state energy and geometry of the cluster are optimized as the distance between the two closest hydrogen atoms is varied, the barrier configurations of the reactants $a^{\prime}$ and $b^{\prime}$, shown in Figures 14, 15, and Figure $16 \mathrm{~b}$, respectively, were determined (the geometrical parameters corresponding to the structures shown in Figures 14 and 16 are given in Table 1).

The barrier configuration is characterized by the formation of a "quasi-hydrogen molecule", $d_{\mathrm{H}-\mathrm{H}}=1.28 \AA$, between the two interacting hydrogens in Figures 14 and 15, compared to $d_{\mathrm{H}-\mathrm{H}}=0.7577 \AA$ in a free $\mathrm{H}_{2}$ molecule, and $d_{\mathrm{H}-\mathrm{H}}=2.331 \AA$

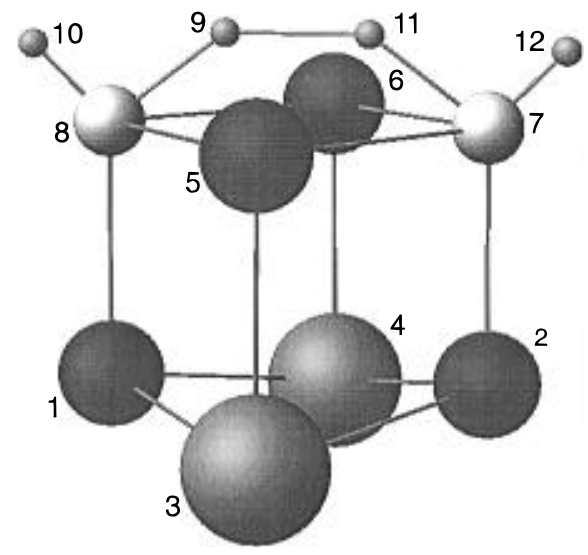

Figure 14. Geometry of $\mathrm{Na}_{4} \mathrm{Cl}_{2}\left(\mathrm{H}_{2} \mathrm{O}\right)_{2}$ at the barrier configuration. The distance between the two interacting hydrogens ( 9 and 11) is 1.28 $\AA$, and the distance between the midpoint of the line connecting the two interacting hydrogens and the upper plane of the sodium chloride cluster is $0.795 \AA$; the intramolecular distances between an oxygen atom and the hydrogens in $\mathrm{H}_{2} \mathrm{O}$ are 0.958 and $1.312 \AA$, with the larger value corresponding to the distance to the interacting hydrogen atom, and the intermolecular angle $\angle \mathrm{HOH}=97.8^{\circ}$.

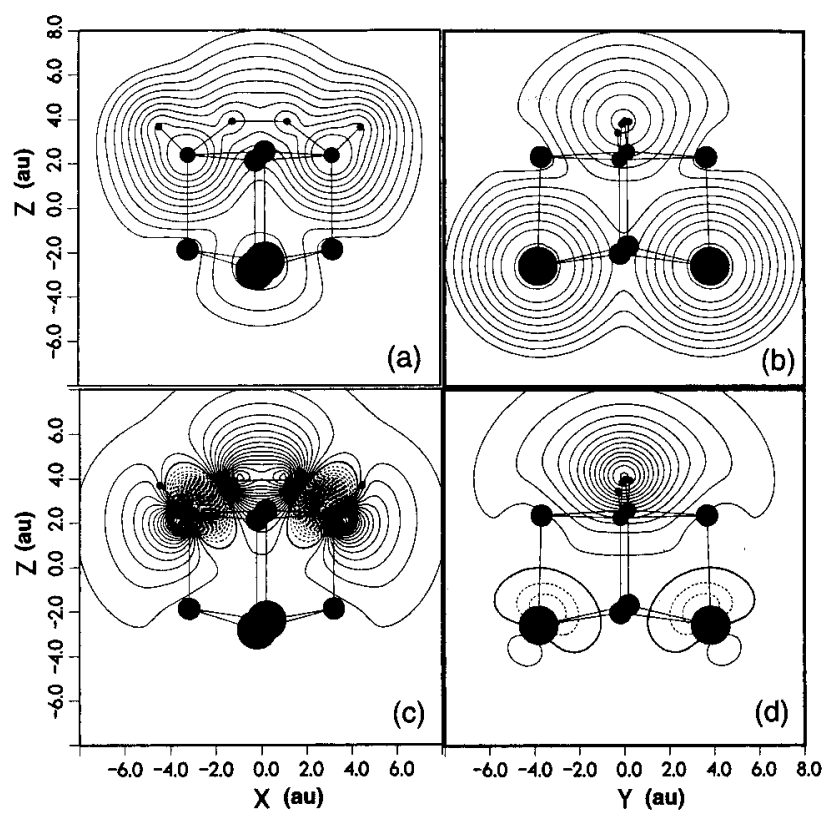

Figure 15. Same as Figure 13, but for $\mathrm{Na}_{4} \mathrm{Cl}_{2}\left(\mathrm{H}_{2} \mathrm{O}\right)_{2}$ at the barrier configuration. Note the formation of a "quasi hydrogen molecule", seen in particular in (c).

between the two closest hydrogens of the two water molecules in the equilibrium configuration of the hydrated $\mathrm{Na}_{4} \mathrm{Cl}_{2}\left(\mathrm{H}_{2} \mathrm{O}\right)_{2}$ cluster; see Figure 10d; the distance between the midpoint of the $\mathrm{H}-\mathrm{H}$ "bond" of the quasi-molecule and the inter-oxygen line in Figure 14 is $0.795 \AA$ compared to $0.415 \AA$ in the hydrated cluster; the intramolecular distance between a reacting hydrogen $\left(\mathrm{H}^{\prime}\right)$ and the oxygen atom is $1.31 \AA$ and the intermolecular $\angle \mathrm{HOH}^{\prime}=97.8^{\circ}$, compared to $0.96 \AA$ and $102.6^{\circ}$, respectively, in the equilibrium configuration. As seen from Figure 5, formation of the barrier configuration is accompanied by some rearrangement of the KS energy levels (compare to the one corresponding to the equilibrium configuration of $\mathrm{Na}_{4} \mathrm{Cl}_{2}$ $\left.\left(\mathrm{H}_{2} \mathrm{O}\right)_{2}\right)$, although the excess electron level (HOMO) is still occupied. Further evolution of the reaction ${ }^{37}$ occurs by simultaneous contraction of the interhydrogen bond and lifting of the $\mathrm{H}_{2}$ molecule from the remaining $\mathrm{Na}_{4} \mathrm{Cl}_{2}(\mathrm{OH})_{2}$ crystallite surface, accompanied by disappearance of the excess electrons level due to formation of hydroxyl anions in the final cluster (see the KS level scheme marked $\mathrm{Na}_{4} \mathrm{Cl}_{2}(\mathrm{OH})_{2} \mathrm{H}_{2}$ in Figure 5, 

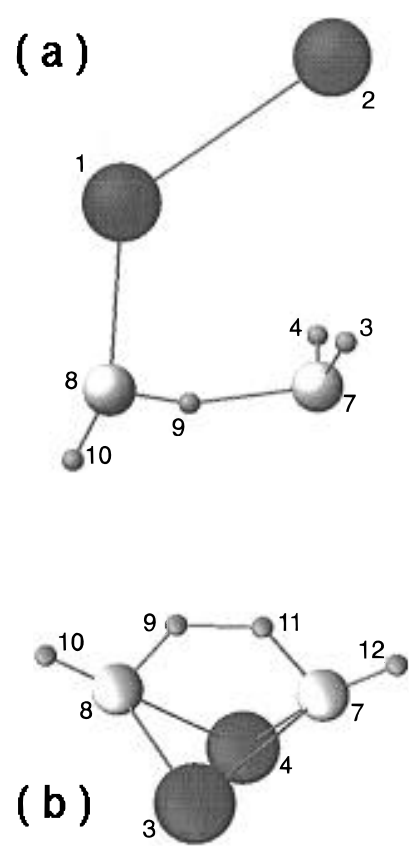

Figure 16. Equilibrium (a) and barrier (b) geometries of $\mathrm{Na}_{2}\left(\mathrm{H}_{2} \mathrm{O}\right)_{2}$. Large dark spheres represent sodium atoms, lighter medium spheres correspond to oxygens, and the smallest ones represent the hydrogens. In the equilibrium configuration (a), $d_{\mathrm{Na}-\mathrm{Na}}=3.10 \AA$, the shortest $d_{\mathrm{Na}-\mathrm{O}}$ distance is $2.25 \AA$, and $d_{\mathrm{O}-\mathrm{O}}=2.57 \AA$. In the barrier configuration (b), $d_{\mathrm{Na}-\mathrm{Na}}=3.38 \AA, d_{\mathrm{Na}-\mathrm{O}}=2.34 \AA, d_{\mathrm{O}-\mathrm{O}}=2.53 \AA$, and the distance between the two interacting hydrogens (9 and 11) is $1.05 \AA$.

where the interhydrogen distance in the evolving $\mathrm{H}_{2}$ molecule is $0.767 \AA$ and its distance from the upper plane of the remaining $\mathrm{Na}_{4} \mathrm{Cl}_{2}(\mathrm{OH})_{2}$ cluster is $1.95 \AA$ ).

\section{Summary}

The energetics, structure, and reactions of water with small sodium chloride clusters $\mathrm{Na}_{4} \mathrm{Cl}_{n}, 2 \leq n \leq 4$, and of $\mathrm{OH}$-doped nonstoichiometric clusters $\left(\mathrm{Na}_{4} \mathrm{Cl}_{3}(\mathrm{OH}), \mathrm{Na}_{4} \mathrm{Cl}_{2}(\mathrm{OH})\right.$, and $\mathrm{Na}_{4}$ $\mathrm{Cl}_{2}(\mathrm{OH})_{2}$ ), were investigated employing electronic structure calculations using the local spin-density functional method with (and without) exchange-correlation gradient corrections in conjunction with norm-conserving nonlocal pseudopotentials, structural optimization, and Born-Oppenheimer molecular dynamics simulations.

For the stoichiometric $\mathrm{Na}_{4} \mathrm{Cl}_{4}$ cluster the adsorption energy of a water molecule was found to be $0.49 \mathrm{eV}$ (see Table 2), and in the equilibrium geometry the $\mathrm{H}_{2} \mathrm{O}$ molecule adsorbs on a "(100) facet" of the $\mathrm{Na}_{4} \mathrm{Cl}_{4}$ cuboid, with the molecular plane tilted toward the cluster by $\sim 13^{\circ}$ with respect to the crystallite's surface (see Figures 2 and 10a).

The nonstoichiometric, $\mathrm{Na}_{4} \mathrm{Cl}_{n}, 2 \leq n<4$, clusters, may be regarded as the finite-size analogues of the well-studied single and multiple F-center systems. Indeed earlier investigations ${ }^{14-20}$ have shown that in such clusters the excess electron(s) localizes (localize) in the halide-vacant site(s) and that the energy level populated by the excess electron(s) is split from the bottom of the manifold of the unoccupied states of the corresponding stoichiometric cluster (see Figure 5).

The present studies build upon the past experience, ${ }^{14-20}$ focusing on $\mathrm{OH}$-doped nonstoichiometric clusters $\left(\mathrm{Na}_{4} \mathrm{Cl}_{m}(\mathrm{OH})\right.$, $m=2,3$ and $\mathrm{Na}_{4} \mathrm{Cl}_{2}(\mathrm{OH})_{2}$ ), and on water adsorption on F-center clusters $\left(\mathrm{Na}_{4} \mathrm{Cl}_{3}\left(\mathrm{H}_{2} \mathrm{O}\right), \mathrm{Na}_{4} \mathrm{Cl}_{2}\left(\mathrm{H}_{2} \mathrm{O}\right)\right.$, and $\left.\mathrm{Na}_{4} \mathrm{Cl}_{2}\left(\mathrm{H}_{2} \mathrm{O}\right)_{2}\right)$, including the thermochemistry of several reactions of water with these clusters, and in particular the cluster-catalyzed hydrogen generation reaction $\mathrm{Na}_{4} \mathrm{Cl}_{2}\left(\mathrm{H}_{2} \mathrm{O}\right)_{2} \rightarrow \mathrm{Na}_{4} \mathrm{Cl}_{2}(\mathrm{OH})_{2}+\mathrm{H}_{2}$. The main findings of these investigations may be summarized as follows. (i) In $\mathrm{OH}$-doped clusters an $\mathrm{OH}^{-}$anion is formed, substituting for the missing halide anion. The hydroxyl anion(s) is (are) oriented approximately along the body diagonal of the cuboid structure of the cluster (Figure 6). Energetically, clusters in the sequence $\mathrm{Na}_{4} \mathrm{Cl}_{4-m}(\mathrm{OH})_{l}$, with $m=1,2$ and $1 \leq l \leq m$, are similar (see Table 2) to the corresponding undoped clusters, $\mathrm{Na}_{4} \mathrm{Cl}_{4-m+l}$; i.e., $\mathrm{Na}_{4} \mathrm{Cl}_{4}$ and $\mathrm{Na}_{4} \mathrm{Cl}_{3}(\mathrm{OH}), \mathrm{Na}_{4} \mathrm{Cl}_{4}$ and $\mathrm{Na}_{4}$ $\mathrm{Cl}_{2}(\mathrm{OH})_{2}$, and $\mathrm{Na}_{4} \mathrm{Cl}_{3}$ and $\mathrm{Na}_{4} \mathrm{Cl}_{2}(\mathrm{OH})$, may be regarded as homologous.

(ii) A water molecule adsorbed at the halide-vacant (F-center) site, and the excess electron is partially expelled from that site (see Figures 10-13). This effect is correlated with a decrease in the vertical and adiabatic ionization potentials upon water adsorption. The binding energies of a water molecule to nonstoichiometric sodium chloride clusters are in the range of $0.25-0.32 \mathrm{eV}$.

(iii) The hydrogen generation reaction $\mathrm{Na}_{4} \mathrm{Cl}_{2}+2 \mathrm{H}_{2} \mathrm{O} \rightarrow$ $\mathrm{Na}_{4} \mathrm{Cl}_{2}(\mathrm{OH})_{2}+\mathrm{H}_{2}$ is catalyzed by the small cluster which brings the two interacting water molecules into close proximity. The exothermicity of the reaction is $3.45 \mathrm{eV}$, and it involves a barrier of $0.33 \mathrm{eV}$. A "quasi hydrogen molecule" is formed in the barrier configuration (see Figures 14 and 15c).

Acknowledgment. This research is supported by the U.S. Department of Energy and the AFOSR. Calculations were performed on Cray computers at the National Energy Research Computer Center, Livermore, CA, and at the Georgia Institute of Technology Center for Computational Materials Science.

\section{References and Notes}

(1) Prospero, J. M.; Mohnen, V.; Jaenicke, R.; Charlson, R. J.; Delany, A. C.; Moyer, J.; Zoller, W.; Rahn, K. Rev. Geophys. Sae Phys. 1983, 21, 1607.

(2) Blanchard, D. C.; Woodcock, A. H. Ann. N.Y. Acad. Sci. 1980, 338,330 .

(3) Warneck, P. Chemistry of the Natural Atmosphere; Academic: San Diego, CA, 1988.

(4) Finlayson-Pitts, B. J. Nature 1983, 306, 676.

(5) Finlayson-Pitts, B. J.; Ezell, M. J.; Pitts, J. N., Jr. Nature 1989, $337,241$.

(6) Keene, W. C.; Pszenny, A. A. P.; Jacob, D. J.; Duce, R. A.; Galloway, J. N.; Schultz-Tokos, J. J.; Sievering, H.; Boatman, J. F. Global Biogeochem. Cycles 1990, 4, 407.

(7) Pszenny, A. A. P.; Keene, W. C.; Jacob, D. J.; Fan, S.; Maben, J. R.; Zetwo, M. P.; Springer-Young, M.; Galloway, J. N. Geophys. Res. Lett. 1993, 20, 699 .

(8) Leu, M.-T.; Timonen, R. S.; Keyser, L. F.; Yung, Y. L. J. Phys. Chem. 1995, 99, 13203.

(9) Dai, D. J.; Peters, S. J.; Ewing, G. E. J. Phys. Chem. 1995, 99, 10299 .

(10) Bruch, L. W.; Glebov, A.; Toennies, J. P.; Weiss, H. J. Chem. Phys. 1995, 103, 5109.

(11) Solomon, S. Nature 1990, 347, 347.

(12) Livingston, F. E.: Ph.D. Thesis, University of California, Los Angeles, 1995. Livingston, F. E.; Whetten, R. L. unpublished work.

(13) Hollenbach, D.; Salpeter, E. E. Appl. J. 1971, 163, 155.

(14) Landman, U.; Scharf, D.; Jortner, J. Phys. Rev. Lett. 1985, 54, 1860.

(15) Barnett, R. N.; Landman, U.; Scharf, D.; Jortner, J. Acc. Chem. Res. 1988, 22, 350.

(16) Rajagopal, G.; Barnett, R. N.; Nitzan, A.; Landman, U.; Honea, E.; Labastie, D.; Homer, M. L.; Whetten, R. L. Phys. Rev. Lett. 1990, 64, 2933.

(17) Rajagopal, G.; Barnett, R. N.; Landman, U. Phys. Rev. Lett. 1991, $67,727$.

(18) Langman, U.; Barnett, R. N.; Cleveland, C. L.; Rajagopal, G. In Physics and Chemistry of Finite Systems: From Clusters to Crystals; Jena, P., Khanna, S. N., Rao, B. K., Kluwer: Dordrecht, 1992; Vol. 1, p 165. (19) Hakkinen, H.; Barnett, R. N.; Landman, U. Europhys. Lett. 1994, 28, 263; Chem. Phys. Lett. 1995, 232, 79.

(20) Barnett, R. N.; Cheng, H.-P.; Hakkinen, H.; Landman, U. J. Phys. Chem. 1995, 99, 7731.

(21) Pollack, S.; Wang, C. R. C.; Kappes, M. M. Chem. Phys. Lett. 1990, 175, 209; Z Phys. D 1989, 12, 241.

(22) Yang, Y. A.; Conover, C. W.; Bloomfield, L. A. Chem. Phys. Lett. 1989, 158,279 
(23) Weiss, P. W.; Ochsenfeld, O.; Ahlrichs, R.; Kappes, M. M. J. Chem. Phys. 1992, 97, 2553.

(24) Bonacic-Koutecky, V.; Fuchs, C.; Gaus, J.; Koutecky, J. Z. Phys. D 1993, 26, 192

(25) Sarkas, H. W.; Kidder, L.; Bowen, K. H. J. Chem. Phys. 1995, $102,57$.

(26) Barnett, R. N.; Landman, U. Phys. Rev. B 1993, 48, 2081.

(27) Troullier, N.; Martins, J. L. Phys. Rev. B 1991, 43, 1993.

(28) Becke, A. D. Phys. Rev. A 1988, 38, 3098; J. Chem. Phys. 1992, 96, 2155.

(29) Perdew, J. P.; Wang, Y. Phys. Rev. B 1991, 44, 13298; 1991, 43 8911; 1992, 49, 13244.

(30) For recent calculations of pathways and dynamics of ionized water dimers using the BO-LSD-MD method, with generalized exchange- correlation gradient corrections, see: Barnett, R. N.; Landman, U. J. Phys. Chem. 1995, 99, 17305 .

(31) Physics of Color Centers; Fowler, W. B., Ed.; Academic: New York, 1968.

(32) Shepherd, I.; Feher, G. Phys. Rev. Lett. 1965, 15, 194

(33) Barraclough, P. B.; Hall, P. G. Surf. Sci. 1974, 46, 393.

(34) Folsch, S.; Henzler, M. Surf. Sci. 1991, 247, 269.

(35) Wedding, B.; Klein, M. V. Phys. Rev. 1969, 177, 1274

(36) Atkins, P. W. Physical Chemistry, 4th ed.; Freeman: New York, 1990.

(37) Barnett, R. N.; Landman, U. Phys. Rev. Lett., to be published.

JP9605764 